\title{
Technical features of a ninth-century silver vessel of southern China uncovered from Famen Monastery, Shaanxi province
}

\author{
Panpan Tan ${ }^{1}$, Junchang Yang ${ }^{2^{*}}$ and Xinlai Ren ${ }^{3}$
}

\begin{abstract}
Silver art is an important feature of the Tang dynasty in China and the manufacturing center for silver shifted from north to south after the mid-eighth century CE. The typology, stylistics, and iconography of silver vessels from both regions have been studied in detail. However, their technical characteristics have rarely been discussed, in particular, those of the southern ones. The current study presents a non-invasive scientific analysis on a partially-gilded silver box from Jiangnanxidao of Tang (southern China), uncovered from the pagoda crypt of the Famen Monastery, Shaanxi province. The results reveal that the box was made of refined silver from cupellation, and composed of five pieces, brazed together with hard solder. Ag-Cu alloy was identified to braze the ring foot and the box bottom. Brazing, hammering, engraving, repoussé, chasing, punching, and partial fire-gilding were employed to shape and decorate the box. More strikingly, the comparative analysis of technical details between this southern box and the previously reported northern silver vessels demonstrates that the former is more precise. Moreover, the similarities in motif expressions of southern-origin silver vessels after the mid-eighth century CE and northern-origin silver vessels before the mid-eighth century CE reflect the inheritance of decorative style. These differences and inheritance indicate that southern artisans after the mid-eighth century CE inherited the decorative technology of the northern-origin silver vessels before the mid-eighth century CE and developed them to greater perfection. The current study presents novel insights into the silver technology of southern China during the late Tang dynasty.
\end{abstract}

Keywords: Silver vessel, Repoussé, Chasing, Partial fire-gilding, Brazing, Famen Monastery

\section{Introduction}

Tang dynasty (618-907 CE) is considered as the "Golden Age" among different dynasties in China, since the period saw great achievements and peak level in precious artworks including silver-based creation [1-3]. The gold and silver vessels of this period are the epitome of multiple cultural and technical influences, such as of Central Asia, West Asia, and the Mediterranean [4-8]. Interestingly, the gold and silver vessels possess similar forms and decorations, which require

\footnotetext{
*Correspondence: yangjunchang@nwpu.edu.cn

${ }^{2}$ Institute of Culture and Heritage, Northwestern Polytechnical University, 127 Youyi Road, Xi'an 710072, China

Full list of author information is available at the end of the article
}

diverse technical skills, such as casting, hammering, repoussé, chasing, engraving, fire-gilding, filigree, granulation, openwork, rivet, soldering, and inlay [6]. Based on the typology, stylistics, and iconography studies, silver vessels of the Tang period are divided into various stages $[3,6]$. Among them, the mid-eighth century CE was an important point-in-time, when the An Lushan rebellion (755-763 CE) occurred $[6,9,10]$. This revolt declined the country's economy, resulting in the shifting of the economic center of the country from the north to the south. Consequently, silver vessels before and after the mid-eighth century $\mathrm{CE}$ show distinct characteristics. Before the mid-eighth century CE, silver vessels, including their form and decorative style, were strongly affected by the exotic culture and they
Springer Open

(c) The Author(s) 2021. This article is licensed under a Creative Commons Attribution 4.0 International License, which permits use, sharing, adaptation, distribution and reproduction in any medium or format, as long as you give appropriate credit to the original author(s) and the source, provide a link to the Creative Commons licence, and indicate if changes were made. The images or other third party material in this article are included in the article's Creative Commons licence, unless indicated otherwise in a credit line to the material. If material is not included in the article's Creative Commons licence and your intended use is not permitted by statutory regulation or exceeds the permitted use, you will need to obtain permission directly from the copyright holder. To view a copy of this licence, visit http://creativeco mmons.org/licenses/by/4.0/. The Creative Commons Public Domain Dedication waiver (http://creativecommons.org/publicdomain/ zero/1.0/) applies to the data made available in this article, unless otherwise stated in a credit line to the data. 
were popular among the nobles [6]. After that period, silver vessels were localized and more widely used among common people [6]. Moreover, these differences in form and decorative style are also prominent in silver vessels uncovered from different regions, i.e., the north and south of China. Ran $[11,12]$ believed that northern silver vessels experienced a period of foreign influence and finally they were localized; however, their further development was interrupted by the An Lushan rebellion. Nonetheless, the manufacturing industry of southern silver began to rise and prosper after the mideighth century CE, when the silver vessels were more decorative than their northern counterparts.

However, technical features of silver vessels from northern and southern regions have rarely been comprehensively discussed. Only a few reports focused on some of the northern-style silver vessels, recovered from Shaanxi, Henan, and Gansu [13-15]. Ma et al. [13] have carried out the metallographic analysis of silver pieces from a gilded silver cup, uncovered from a Tubo tomb (mid-eighth century CE) in the Dachangling cemetery of Gansu province. Though they confirmed the utilization of fire-gilding decoration, the decorative techniques have not been discussed in detail. Tan et al. [14] carried out the non-destructive analysis of three silver vessels, discovered from the Wei family cemetery (early eighth century CE) in Xi'an city, Shaanxi province. They have focused on the investigation of decorative methods. Furthermore, the tool marks of seven punches were recognized. Yao et al. [15] analyzed a gilded silver box, uncovered from the Xiaolizhuang site (mid-eighth century CE) in Henan province, by nondestructive methods to perform a detailed investigation on box decorations. They have identified decorative techniques and clarified the manufacturing procedures. These studies provide a preliminary understanding of manufacturing techniques of silver vessels from northern regions during and before the mid-eighth century CE. Nevertheless, the comprehensive understanding of metalwork during the Tang dynasty requires further systematic explorations, in particular, about the technical details of silver vessels after the mid-eighth century $\mathrm{CE}$ in southern China.

The current study presents a technical analysis of a southern silver box (ninth century CE) uncovered from the Tang pagoda crypt of Famen Monastery in Shaanxi province, China. Based on the non-destructive analysis, such as structural, compositional, and decoration technical analyses, the results revealed manufacturing techniques and decorative details of repoussé, chasing, punching, and partial fire-gilding. This study can enhance our understanding of silverwork techniques during the Tang dynasty.

\section{Material and methods Material}

Famen Monastery, located in Famen town of Fufeng county, Baoji city, west of Xi'an, Shaanxi province, China (Fig. 1a), has attracted extensive research interest due to the discovery of four miraculous Buddhist finger bone relics and a large number of delicate tributes for the true body relic $[16,17]$. These diverse tributes were uncovered from the underground palace of the Tang pagoda in the 1980s (Fig. 1b), where 336 items in total were unearthed, including 118 gold and silver artifacts, 35 textiles, 20 glassware, 16 porcelains, 70 bronzes and irons, 26 wooden lacquered objects, 11 stoneware, and 40 gems [16]. According to the stone Yiwuzhang (inventory stele), these treasures were placed in the pagoda crypt in 874 $\mathrm{CE}$ and most of them were donated by Emperor Yizong (833-873 CE) and Xizong (862-888 CE) of Tang, while some were offered by senior monks and eunuchs [18]. Moreover, the inscriptions on the gold and silver vessels suggest a variety of provenances, e.g., the products from the imperial workshop were labeled as "Wensiyuan", established in 854 CE in Chang'an (modern Xi'an), and the tributary gifts from regional officials were marked with the officials' names and their jurisdiction areas [18, 19].

A delicate silver box, found in the southeast corner of the rear chamber (Fig. 1c), was analyzed in this study. This box is in a floral shape and possesses straight walls, a plain bottom, and a splayed high ring foot (Fig. 2a, b). The lid cover is decorated in high relief on the front with two lions leaping and chasing each other in the center. The lions are surrounded with scrolling passionflowers also in high relief. These motifs are reserved on a ringmatted background and enclosed by a rhombus frame of raised pearl roundel. Outside the rhombus frame, the four corners of the lid cover are filled with four pairs of raised passionflowers, also on a ring-matted background; the rim of the lid cover is decorated with raised lotus petals (Fig. 2a, c). The box walls are decorated with scrolling lotus on a ring-matted background, and the rim of the ring foot is decorated with lotus leaves (Fig. 2b). Except for the matted ground, the relief motifs on the lid cover, main motifs on the box walls, and lotus leaves on the ring foot all were gilded (Fig. 2a).

More importantly, source information was found on the box. The Chinese-inked Neiku on the front of the lid cover (Fig. 2c) indicates that the box was collected in the royal storeroom [18]. The inscription was found on the outer surface of the bottom, i.e., a gilded box with length of $6 \mathrm{Cun}$ and weight of 20 Liang was presented by the official Li of Jiangnanxidao, to the Emperor of the Tang Empire for celebrating the Yanqing festival (Fig. 2d). Jiangnanxidao represents the 


\section{a}
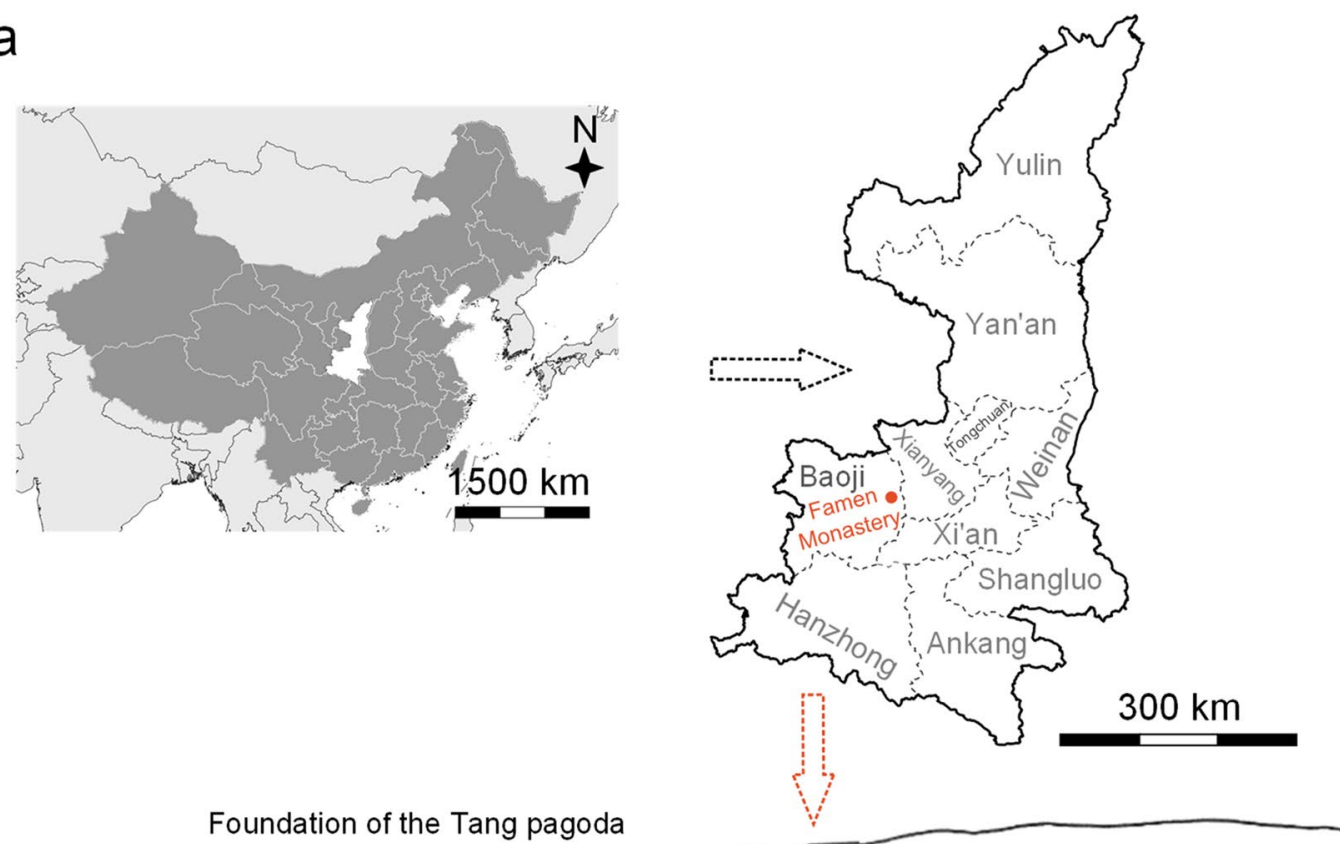

b

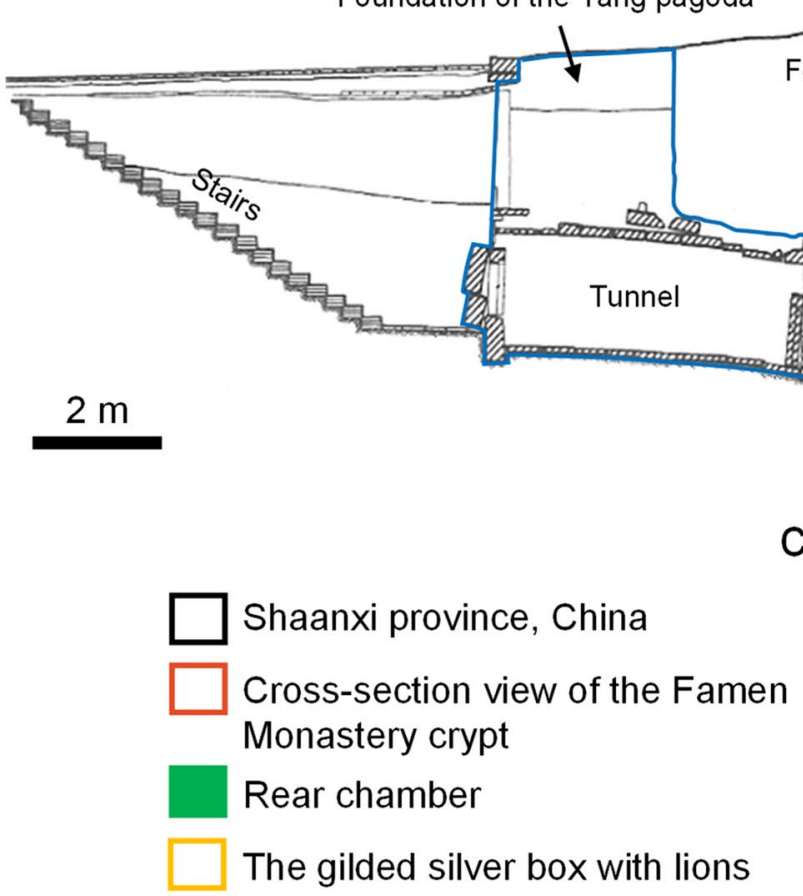

Foundation of the Ming pagoda

C

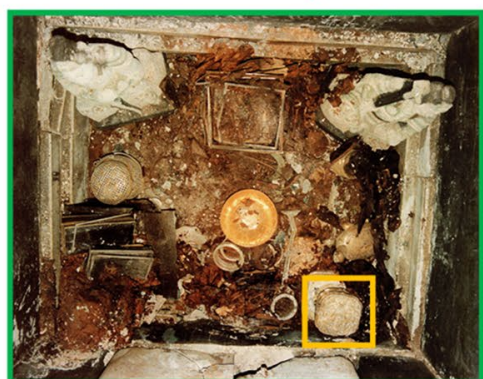

Fig. 1 a Geographical map of Famen Monastery; $\mathbf{b}$ cross-sectional view of stupa foundation and underground palace [16]; and $\mathbf{c}$ the location of the partially gilded silver box [20]

regions around the modern Nanchang city of Jiangxi province. Yanqing festival was established in $859 \mathrm{CE}$ for celebrating the birthday of Emperor Yizong [21]. In summary, this box was first made in southern China, then it was presented to Emperor Yizong and stored in Neiku, and finally, it was taken to Famen Monastery in $874 \mathrm{CE}$. Therefore, this silver box was probably produced during the second half of the ninth century $\mathrm{CE}$. The length, width, height, and mass of the box are $17.3 \mathrm{~cm}, 16.8 \mathrm{~cm}, 11.2 \mathrm{~cm}$, and $799 \mathrm{~g}$, respectively [16]. 

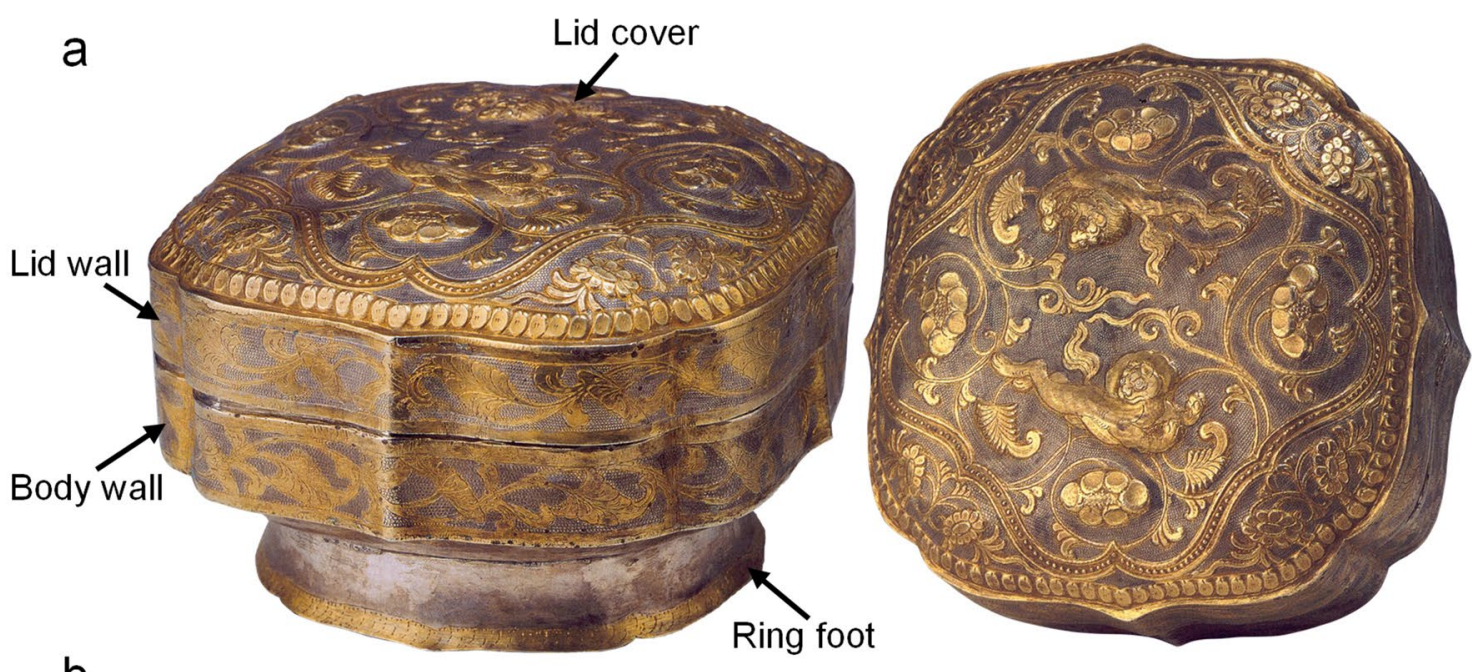

b

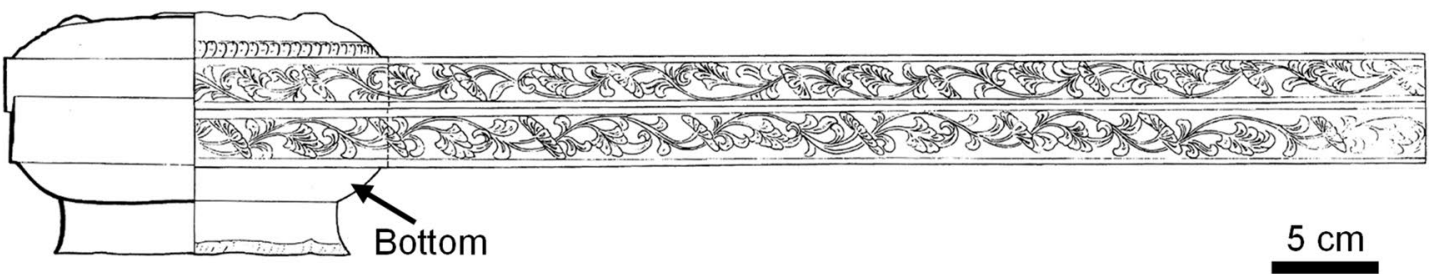

C

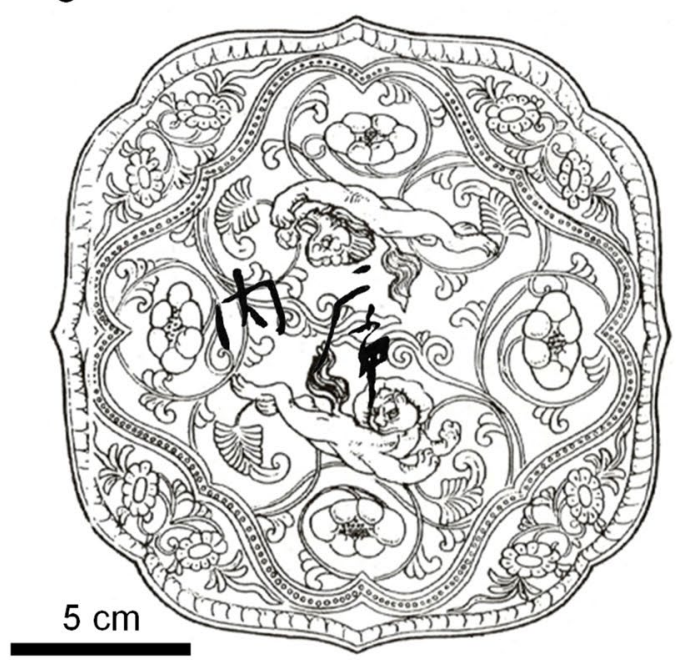

d

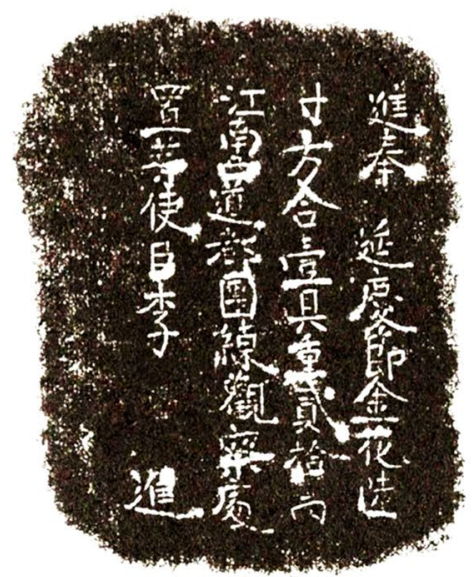

Fig. 2 a Digital photographs of the silver box (left) and motif on the lid cover (right) [20]; b line drawing of the side view and motif on the box walls [16]; c line drawing of the motif and Chinese-inked Neiku on the lid cover [16]; and $\mathbf{d}$ the inscription on the outer surface of the bottom [16]

\section{Methods}

The studied silver box is stored in the Famen Temple Museum. It was not allowed to take the box out of the museum for conventional laboratory analysis. Only portable analytical instruments with permission, such as the microscope and X-ray fluorescence (XRF) spectrometer, were permitted into the museum to conduct the non-destructive analysis.

\section{Microscopic analysis}

The structure, morphology, and tool marks of the box were investigated using a three-dimensional digital 
microscope (KEYENCE VHX-600, Japan) and recorded with high-resolution $(1600 \times 1200$ pixels $)$ images. An objective lens of VH-Z20R was used in this study, which has a magnification of $20-200 \mathrm{X}$ and a depth of field ranging from 34 to $0.44 \mathrm{~mm}$. The microscope consists of a $100 \mathrm{~W}$ halogen lamp cold light source. Therefore, the color of the image obtained using the microscope gets influenced by the yellow light. In order to obtain the original color of the gilded silver box, the white balance of the micrographs was corrected by using the Adobe Photoshop 13.0 software.

\section{Compositional analysis}

Different components of the box were analyzed using a handheld portable XRF spectrometer (p-XRF, Thermo Niton XL3t800, USA) equipped with a $2 \mathrm{~W}, 50 \mathrm{kV}$ silver anode X-ray tube and high-performance silicon drift detector. The mode for alloy is divided into three modes due to certain elements. Precious Metals mode (effective testing diameter: $8 \mathrm{~mm}$ ) is for the analysis of precious metal, including elements $\mathrm{Ag}, \mathrm{Au}, \mathrm{Cu}, \mathrm{Zn}, \mathrm{Fe}, \mathrm{Pb}$, Ir, Ti, Cr, Mn, Co, Ni, Ga, Nb, Mo, Ru, Rh, Pd, Cd, In, Sn, and $\mathrm{Pt}$, where the platinum family element is included. Standard Alloy mode (effective testing diameter: $3 \mathrm{~mm}$ ) is for the analysis of the unknown metal, including elements $\mathrm{Ag}, \mathrm{Au}, \mathrm{Cu}, \mathrm{Zn}, \mathrm{Fe}, \mathrm{Pb}, \mathrm{Al}, \mathrm{Ti}, \mathrm{V}, \mathrm{Cr}, \mathrm{Mn}, \mathrm{Co}, \mathrm{Ni}$, As, Se, Zr, Nb, Mo, Ru, Pd, Cd, Sn, Sb, Hf, Ta, W, Re, and $\mathrm{Bi}$, where more metallic elements are included. Electronics Alloy mode (effective testing diameter: $3 \mathrm{~mm}$ ) is for the analysis of the metal coating, including elements $\mathrm{Ag}$, $\mathrm{Au}, \mathrm{Cu}, \mathrm{Zn}, \mathrm{Fe}, \mathrm{Pb}, \mathrm{Hg}, \mathrm{Al}, \mathrm{Ti}, \mathrm{V}, \mathrm{Cr}, \mathrm{Mn}, \mathrm{Co}, \mathrm{Ni}, \mathrm{Se}, \mathrm{Br}$, $\mathrm{Zr}, \mathrm{Nb}, \mathrm{Mo}, \mathrm{Pd}, \mathrm{Cd}, \mathrm{In}, \mathrm{Sn}, \mathrm{Sb}, \mathrm{Ba}, \mathrm{Hf}, \mathrm{Ta}, \mathrm{W}, \mathrm{Pt}$, and Bi, where Hg could be measured. These different modes have little effect on the content of main elements.

In the current study, Precious Metals mode was used to analyze the base of the box, Standard Alloy mode was employed to analyze the joining area, and Electronics Alloy mode was utilized to explore the gilt layer. Moreover, the measuring head touched the tested surface during the analysis. Notably, 3-5 measurements were conducted on every component of the box and the valid data were incorporated into the final reported result. The measurement time for each spot analysis was $30 \mathrm{~s}$ and the elemental results detected were normalized.

\section{Results}

\section{Structure and composition}

The microscopic investigations of the gilded silver box reveal that the box was composed of five parts, including the lid cover, lid wall, body wall, bottom of the box, and the ring foot (Fig. 2a, b). The p-XRF spectroscopy results demonstrate that these components were made of refined silver (Table 1 ).

Presence of solder was observed at the joint between the lid cover and lid wall, joint between the body wall and box bottom, joint between the box bottom and ring foot, joint of lid wall, joint of the body wall, and joint of ring foot (Fig. 3a, b; Additional file 1: Fig. S1). These solder are in silver color (Fig. 3a) and some are with green corrosion (Additional file 1: Fig. S1), indicating that metal alloy solder with copper was used to bond these components. Moreover, two pieces of metal in silver color were found at the joining area between the box bottom and ring foot (Fig. 3b), indicating that alloy solder in the form of platelets was used by the Tang's artisan to braze different

Table 1 p-XRF spectroscopy results of the partially-gilded silver box

\begin{tabular}{|c|c|c|c|c|c|c|c|c|c|c|}
\hline \multirow[t]{2}{*}{ Analysis zone } & & \multirow[t]{2}{*}{ Analysis mode } & \multicolumn{8}{|c|}{ Composition (wt. \%) } \\
\hline & & & $\mathrm{Ag}$ & $\mathrm{Au}$ & $\mathrm{Cu}$ & $\mathrm{Hg}$ & $\mathrm{Fe}$ & $\mathrm{Pb}$ & Ir & $\mathrm{Zn}$ \\
\hline Back of box lid (no gilding) & Micro-area & Precious alloy & 97.5 & 1.1 & 0.8 & & & 0.6 & & \\
\hline \multirow[t]{3}{*}{ Bottom of box body (no gilding) } & Micro-area & Precious alloy & 99.4 & & 0.2 & & 0.3 & & 0.1 & \\
\hline & Micro-area & Precious alloy & 99.5 & & 0.2 & & 0.1 & & 0.2 & \\
\hline & Micro-area & Precious alloy & 98.8 & & 0.4 & & 0.6 & & 0.2 & \\
\hline \multirow[t]{2}{*}{ Ring foot } & Micro-area & Precious alloy & 97.0 & 1.3 & 0.8 & & 0.4 & & 0.5 & \\
\hline & Micro-area & Precious alloy & 97.0 & 1.3 & 0.8 & & 0.4 & & 0.5 & \\
\hline Joining area (box body + ring foot) & Micro-area & Standard alloy & 68.7 & 0.2 & 28.4 & & & 0.1 & & 2.5 \\
\hline \multirow[t]{4}{*}{ Gilt layer (box lid) } & Micro-area & Electronic alloy & 57.1 & 36.7 & & 6.2 & & & & \\
\hline & Micro-area & Electronic alloy & 61.8 & 32.0 & & 6.2 & & & & \\
\hline & Micro-area & Electronic alloy & 59.6 & 33.5 & & 6.9 & & & & \\
\hline & Micro-area & Electronic alloy & 62.6 & 31.6 & & 5.8 & & & & \\
\hline \multirow[t]{2}{*}{ Gilt layer (box body) } & Micro-area & Electronic alloy & 61.6 & 31.9 & & 6.2 & 0.3 & & & \\
\hline & Micro-area & Electronic alloy & 60.4 & 32.7 & & 6.9 & & & & \\
\hline
\end{tabular}



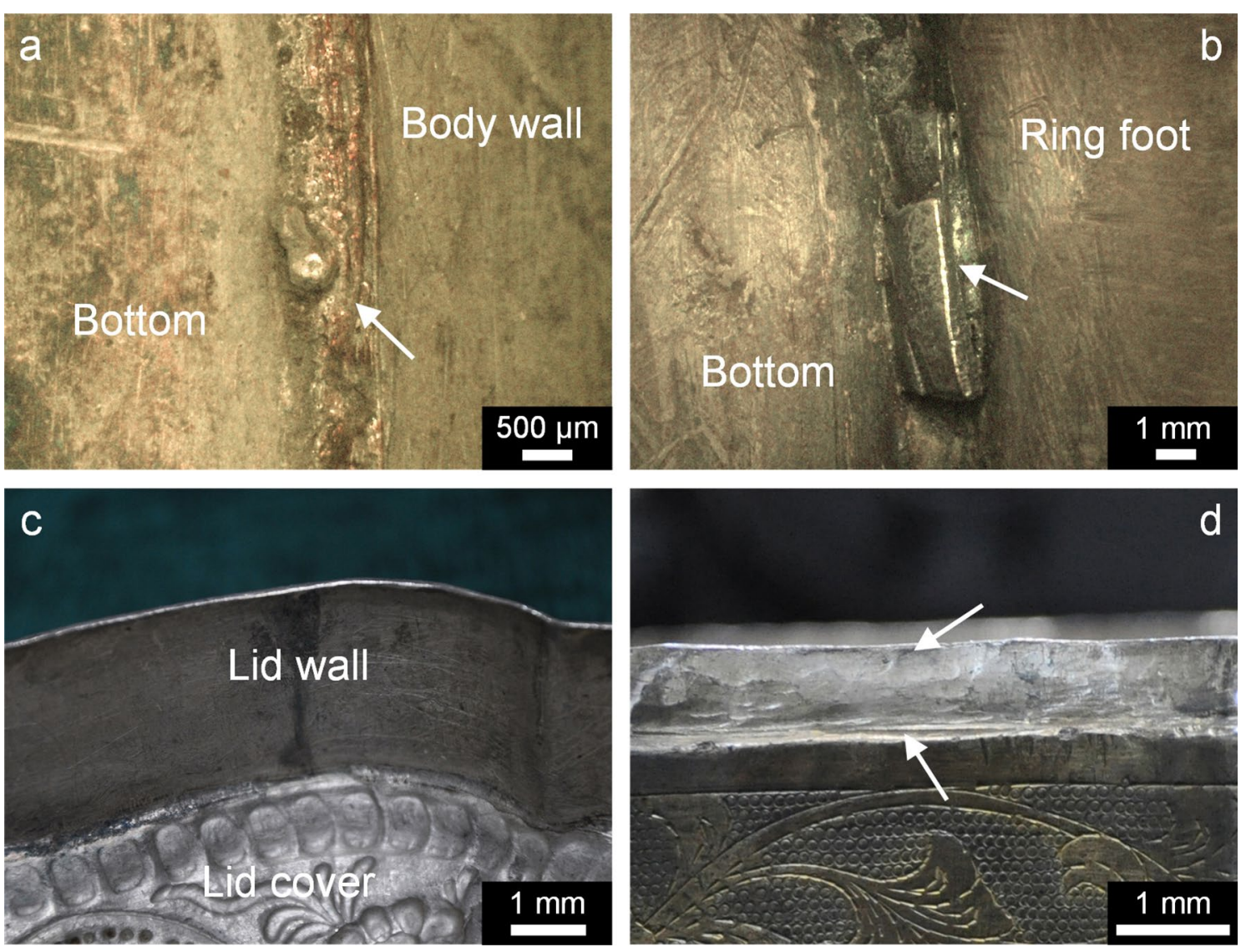

Fig. 3 Typical micrographs of the silver box: a the joint between the box bottom and body wall; $\mathbf{b}$ soldering metals at the joint between the box bottom and ring foot; $\mathbf{c}$ even inner surface of the lid wall; and $\mathbf{d}$ engraved edge of the outer surface of the body wall

parts of the box. Herein, we made an attempt to measure the chemical composition of the solders; however, they (including the solder platelets) were in such narrow positions that it was very difficult to detect their composition. Fortunately, a set of valid data was obtained for the joint between the bottom and the ring foot. The result shows that the solder mainly consisted of silver (Ag), copper $(\mathrm{Cu})$, and zinc $(\mathrm{Zn})$ (Table 1), indicating that silver-based alloy (hard solder) was used to solder the different part of the box.

Furthermore, the box lid and body were mechanically locked together. The lid wall shows an even inner surface (Fig. 3c), whereas the outer rim of the box body is relatively uneven, which was made by engraving to remove silver and then hammering to even the engraved areas, for locking with the box lid (Fig. 3d).

\section{Decorative techniques Dominant motifs}

Clearly, the following two types of dominant designs are present on the box: one is relief motifs on the lid cover; and the other is plane motifs on the box walls and the rim of the ring foot (Fig. 2a, b).

Figure 4 shows typical micrographs of the lid cover. The punch-made small marks are observed on the back of the reliefs (Fig. $4 \mathrm{a}-\mathrm{C}$ ), indicating that the repoussé technique was used to make these relief motifs on the back [22-25]. Besides, the closer observation of the front of the reliefs reveals that they were further enhanced with chased outlines which are composed of overlapping isosceles triangles (Fig. 4d, e). These lines were produced by rapidly hammering a liner punch (with a line end) which quickly moved along the silver at an angle, without the loss of silver [23, 25-27]. This process started from the blunt of the line and finished at its sharp end. On the surface of relief motifs, details were created using various types of punches, e.g., a liner punch with a sharp end was utilized to detail the leaf (Fig. 4a, d), a liner punch with a blunt end was employed to execute the details of lion face (Fig. 4f), and a ring punch (with a ring end) was used to make the lion's eyes (Fig. 4f).

Similar to the relief motifs, the plane motifs and inscription were also created by the chasing technique 

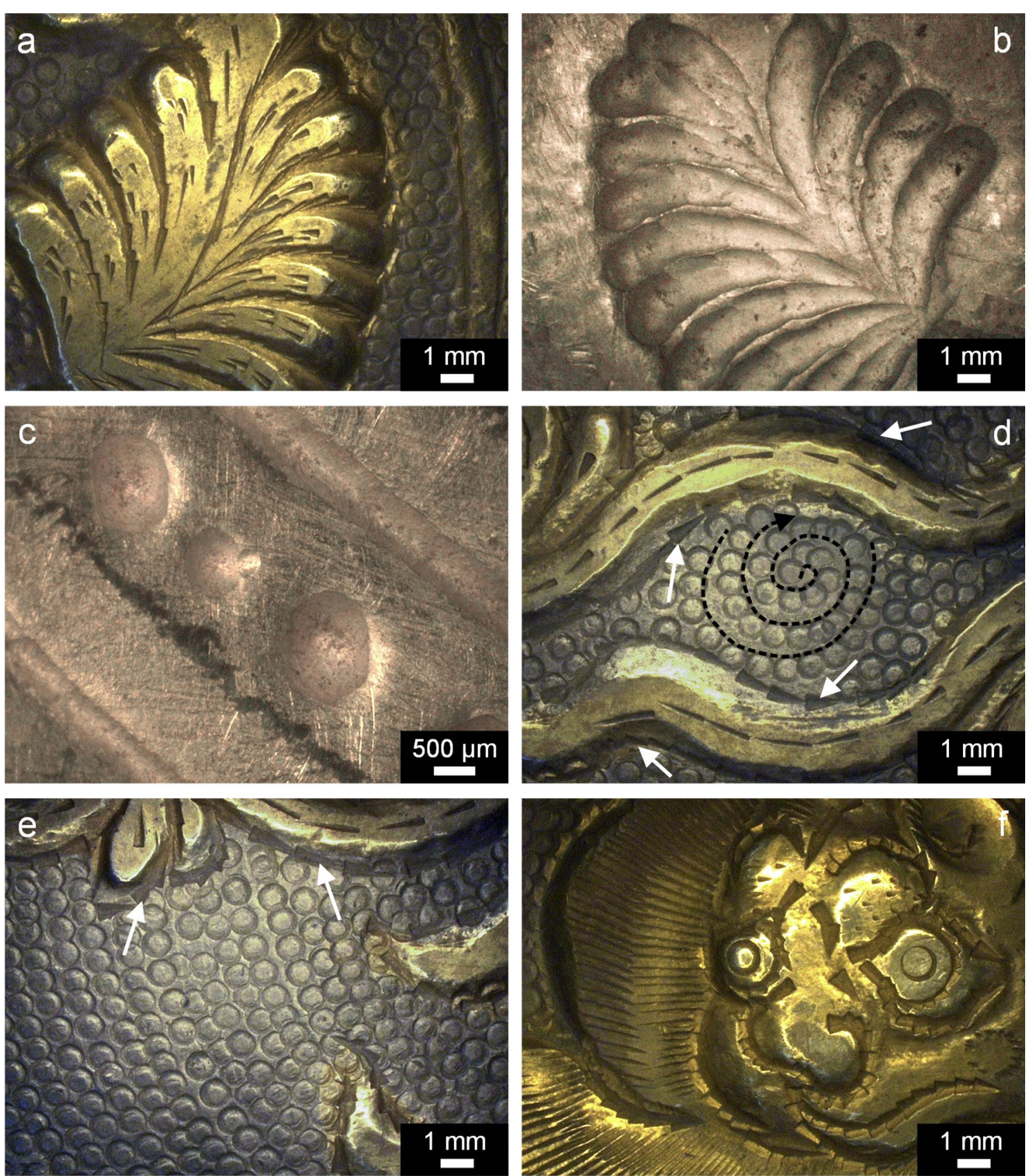

Fig. 4 Typical micrographs of motifs on the lid cover: a front of the passionflower leaf; $\mathbf{b}$ back of the passionflower leaf; $\mathbf{c}$ back of the pearl roundel; $\mathbf{d}$ matted background in the central part of box lid; e matted background next to the center of box lid; and $\mathbf{f}$ front of the lion's head

(Fig. 5a, b). Interestingly, traced marks are found beside the strokes of the inscription (Fig. 5c, d), indicating that the characters were positioned before chasing.

\section{Ring-matted background}

In addition to the major motifs, countless rings are present in the background. They were produced by the punching technique, i.e., rapidly hammering a ring punch which quickly moved along the silver plate to imprint the ring [27]. On the lid cover, these small rings are spirally arranged from the center to the rim (Fig. $4 \mathrm{~d}$, e). On the box walls, the rings are arranged parallel to the rims of the lid wall and body wall (Fig. 5a, b). For the more comprehensive understanding of the ring-matted background, the diameters of 186 rings on the lid were measured, and the results revealed that these rings are very 

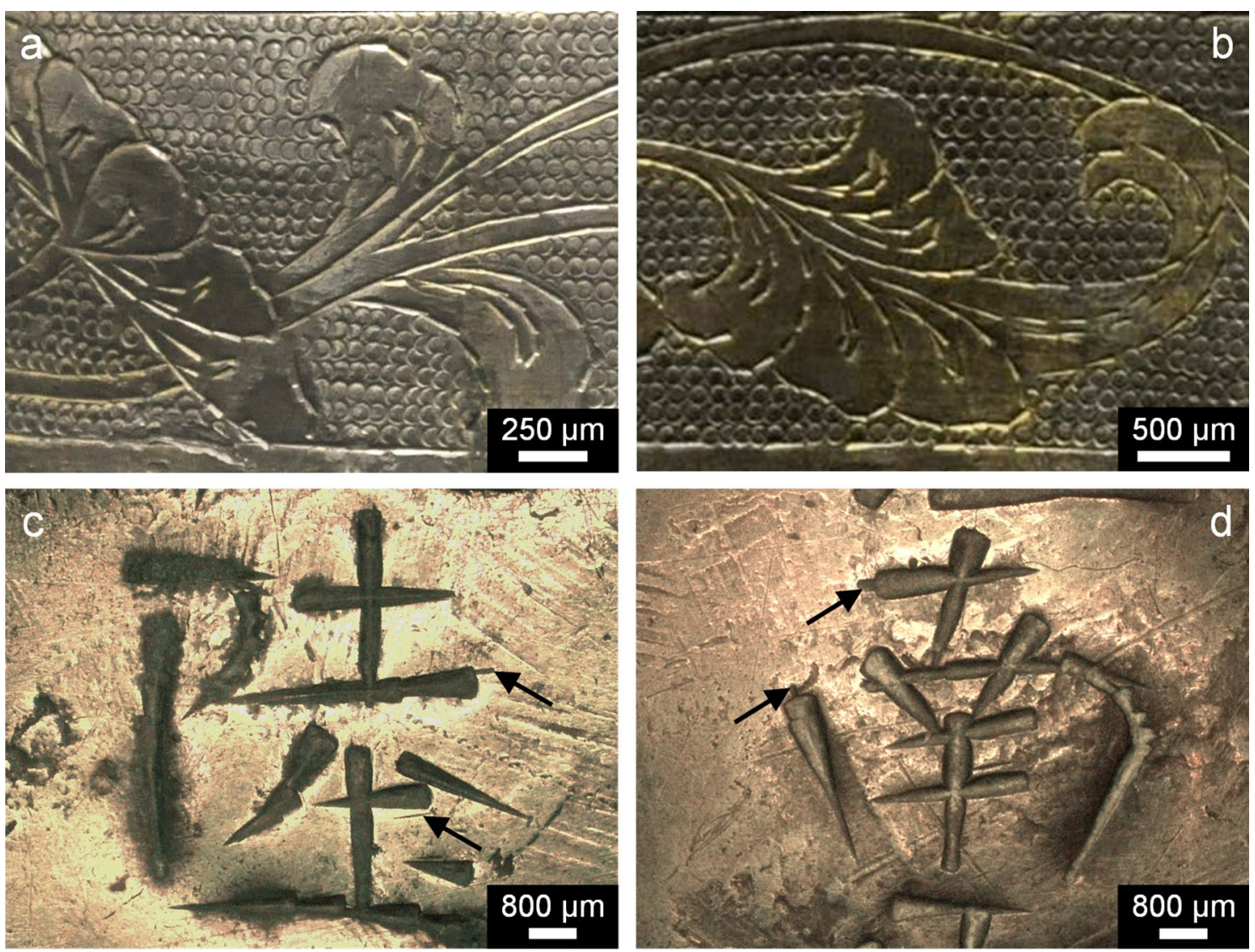

Fig. 5 a Motif on the lid wall; $\mathbf{b}$ motif on the body wall; c the chased character Liu on the box bottom; and $\mathbf{d}$ the chased character Nan on the box bottom

similar in size, i.e., $0.87 \pm 0.05 \mathrm{~mm}$ (Additional file 1: Fig. S2).

\section{Gilding}

Apart from the production of motifs, partial gilding was employed on the dominant motifs to distinguish them from the background. The result of elemental analysis shows that mercury $(\mathrm{Hg})$ and gold $(\mathrm{Au})$ are present in the gilt areas (Table 1), indicating that the fire-gilding technique was used to achieve the golden appearance [28-30].

Besides, the precedence of chasing, punching, and gilding was clarified using the microscope. On the gilded motifs, the chased lines possess smooth rims and clean surfaces (Fig. 4a, d), indicating that these details were created after the application of gilding. On the other hand, few rings next to motifs are covered by the gilding (Fig. 4a, d, and e), suggesting that the rings were punched before the gilding process.

Therefore, the major manufacturing procedure of the partially gilded silver box is summarized below. First, five silver components of the box were prepared. Second, the relief motifs were produced by the repoussé technique and the plane motifs were created by the chasing technique. Third, the matted background was punched with a ring punch. Fourth, fire-gilding was applied. Fifth, the outlines and details of motifs were chased. Finally, the asprepared parts were soldered together with a silver-based hard solder.

\section{Discussion}

\section{Compositional analysis}

Rich mineral resources and lenient policies facilitated the mining and smelting of silver during the Tang dynasty. The record shows that the government allowed private silver mining and more than 58 silver mines were operating under the tax revenue system [6]. Moreover, large amounts of silver were shipped from different parts of the country to the central government and the imperial family [6]. The analysis of a silver slag found in the Hejiacun treasure reveals that the percentage of $\mathrm{Ag}$ was extremely low, which indicates that the silversmiths were able to smelt high-quality silver during the Tang dynasty [31]. The statistics show that most of the silver items of 
the Tang period possess a high percentage of $\mathrm{Ag}$ (> $80 \mathrm{wt}$. $\%)$ (Additional file 1: Table S1). Herein, the composition of the studied silver box and silver fragments from the pagoda crypt fall within most of the data measured in other silver vessels from the places outside the Famen Monastery (Additional file 1: Fig. S3 and Table S1).

In addition to the dominant element $\mathrm{Ag}$, a trace amount of $\mathrm{Pb}$ was also detected in the box lid (0.6 wt. \%) and in the silver-based solder $(0.1 \mathrm{wt}$. \%), respectively (Table 1$)$. Historically, argentiferous lead ore was the most important silver ore [32-35], which was an important source in Tang China [31]. Cupellation was used to refine silver, utilizing the feature that lead has high affinity to silver and is also relatively easy to be separated from silver [31, 36]. During the process, the argentiferous lead was oxidized and most lead was turned into lead oxide (litharge) along with other impurities (e.g., zinc oxide, lead sulfide, zinc sulfide), leaving behind the silver [32, 37-39]. Lead used in this process could either be from the argentiferous lead ore or be added in as part of the furnace charge [40]. Finally, trace amounts of lead were sometimes inevitably left in the silver. More than 80 wt. \% of $\mathrm{Pb}$ detected in the silver slag of the Hejiacun treasure indicated the employment of the cupellation technique [31]. Moreover, we have summarized all the analytical results of the Tang silver objects which were published in other papers. The result shows that $28.2 \%$ of the Tang silver objects contain $\mathrm{Pb}$ varying from $0.01 \mathrm{wt}$ \% to $1.16 \mathrm{wt}$. \% (Additional file 1: Table S1). These minute quantities of lead were probably derived from the refining process of silver by the cupellation technique.

Apart from the base composition of the box, $\mathrm{Ag}, \mathrm{Cu}$ and $\mathrm{Zn}$ were identified in the joint between the box bottom and ring foot. However, there has been no ancient written record and scientific data on the solder used for the silver objects during and before the Tang dynasty. Only two fluxes for promoting soldering silver were mentioned, i.e., Hutonglei (a glue gum from Populus diversifolia) and Lusha $\left(\mathrm{NH}_{4} \mathrm{Cl}\right)[41,42]$. The historical record and analytical data of silver objects after the Tang dynasty provide clues for the soldering of silver items. At the joining area of a silver artifact of the Liao dynasty (916-1125 $\mathrm{CE}), \mathrm{Ag}-\mathrm{Cu}$ alloy was detected as a solder [43]. Ag-Cu$\mathrm{Zn}$ alloy was recorded as a solder for copper objects in the literature of Qing dynasty (1636-1912 CE) [44, 45]. Moreover, $\mathrm{Ag}-\mathrm{Cu}-\mathrm{Zn}$ alloy is used to bond silver objects in modern metallurgy [46].

The content of $\mathrm{Zn}$ in the joint of the currently studied silver box was found to be $2.5 \mathrm{wt}$. \%. According to the $\mathrm{Ag}-\mathrm{Cu}-\mathrm{Zn}$ ternary diagram, the given alloy has a melting point of $\sim 755^{\circ} \mathrm{C}$ [47]. If the influence of $\mathrm{Zn}$ is ignored, the $\mathrm{Ag}-\mathrm{Cu}$ alloy has a melting point of $\sim 785{ }^{\circ} \mathrm{C}$ [47]. The small temperature difference of $30{ }^{\circ} \mathrm{C}$ was not worth the artificial alloying of zinc with $\mathrm{Ag}-\mathrm{Cu}$ alloy by the Tang silversmiths. Moreover, it is known that the Chinese traditional zinc-smelting technology originated during the Ming dynasty (1368-1644 CE) [48]. Therefore, the element $\mathrm{Zn}$ here should not be from the metallic zinc, but was from the impurities associated with silver and copper. Herein, most zinc should correspond to the impurity associated with the copper ore, due that the silver refining process could oxidize/sulfurize the most zinc impurity. Therefore, it is expected that the Ag-Cu alloy should have been employed by the ancient artisan to braze silver box and ring foot.

\section{Decorative techniques}

Remarkably, the repoussé, chasing, punching, and firegilding were employed to create and decorate the motifs of the box. These techniques were commonly used on the Tang's silver vessels. The published technical analyses of silver vessels from the Wei family cemetery and Xiaolizhuang site in northern China also demonstrate the use of these techniques. In the Wei family cemetery, analysis of a silver cup indicates the utilization of chasing and punching, analysis of a small round silver box indicates the use of chasing, punching, and partial firegilding, and analysis of a three-legged silver pot indicates the employment of repoussé, chasing, punching, and partial fire-gilding [14]. Moreover, a silver box from the Xiaolizhuang site used repoussé, chasing, punching, and all-over fire-gilding [15].

Specifically, the ring-matted background was present on the all the aforementioned silver vessels. Figure 6

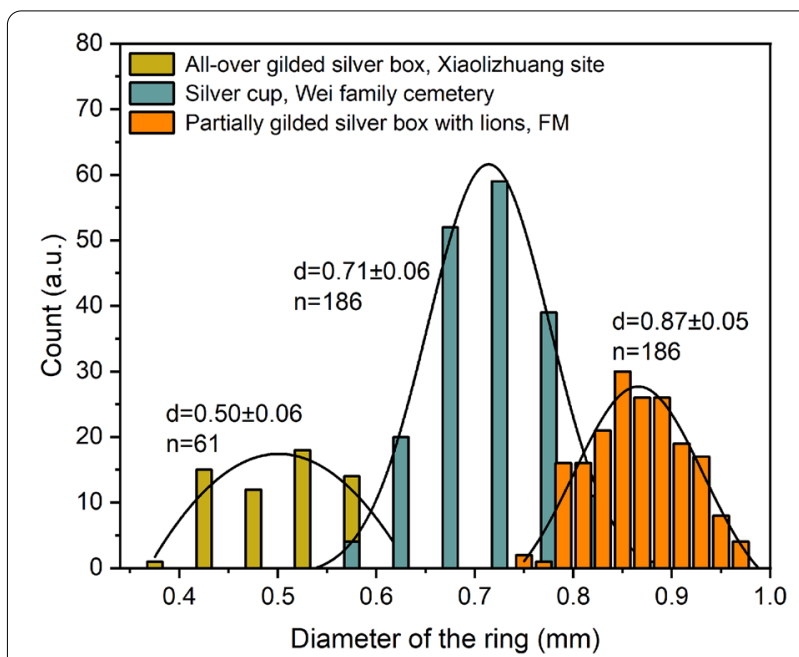

Fig. 6 The ring diameter distributions of the ring-matted backgrounds on the all-over gilded silver box from the Xiaolizhuang site, the silver cup from the Wei family cemetery, and the partially-gilded silver box from the Famen Monastery 
shows the diameter distribution of the rings. The statistical analysis reveals that the ring diameter on three vessels exhibits only a small standard deviation, which indicates that the skilled silversmith of the Tang dynasty was able to accurately control the ring size during the rapid punching process. More strikingly, the ring diameter was closely related to the size of the vessel. To be specific, the gilded silver box of the Xiaolizhuang site exhibits the smallest dimensions and is decorated with a ring-matted background with the smallest ring diameter [15], whereas the silver cup from the Wei family cemetery has medium dimensions and is decorated with a matted background with a medium ring diameter [14] (Fig. 6 and Additional file 1: Figs. S6 and S7). The partially gilded silver box of this study has the maximum dimensions and is decorated with a ring-matted background with the maximum ring diameter (Figs. 4d, e, 6). These results indicate that the silversmiths during the Tang dynasty were experienced in selecting the different sizes of punch end according to the dimensions of the artifacts.

Though the silver vessels from northern and southern regions were prepared by the same techniques and using the same decorative elements, the comparative analysis of their technical details suggests that the southern-origin silver box from the pagoda crypt of Famen Monastery employed more sophisticated technology. The matted backgrounds of the silver box and pot (Wei family cemetery) and the silver box (Xiaolizhuang site) are quite rough with overlapping rings (Additional file 1: Figs. S4b, $\mathrm{S} 5 \mathrm{~b}$ and S7b). Moreover, the rings on the small round box (Wei family cemetery) overlapped so severely that is difficult to recognize the single ring (Additional file 1: Figs. S4b and c) $[14,15]$. Besides, the silver cup of Wei family cemetery (Additional file 1: Fig. S6b) and the currently studied silver box (Fig. 4d, e) possess distinct ringmatted backgrounds, however, the latter contains a more regular ring arrangement [14]. In addition to the matted background, the details of the chased motifs also reflect different technical skills. In the case of silver vessels from the Wei family cemetery, the chased lines on the silver cup are deep, discontinuous, and unsmooth (Additional file 1: Fig. S6c and d); the chasing marks on the threelegged pot are blurred (Additional file 1: Figs. S5c and d); some chased lines on the rim of the small round box are indistinct and unfinished (Additional file 1: Fig. S4d) [14]. With respect to the silver box of the Xiaolizhuang site, the chasing marks are shallower and some are even out of shape (Additional file 1: Figs. S7c and d) [15]. Concerning the currently studied silver box, the chased lines are smooth, and triangular chasing marks are clear (Fig. 4a, $\mathrm{d}$, and $\mathrm{f}$ ).

In terms of decorative techniques, in summary, artisans of the Tang dynasty were skilled at processing of silver vessels, while the artisans in the southern region after the mid-eighth century were more experienced.

\section{Perspective on the manufacturing of southern-origin silver box of the Famen Monastery}

Noteworthy, this gilded silver box with lions was donated by Emperor Yizong as a tribute to the true body relic. On one hand, this box must be one of the most precious gifts of Yizong. On the other hand, it must represent the most sophisticated silver technology of that period, which partly indicates the prosperity of the southern luxury industry in the late Tang dynasty. The major reason for the prosperity of southern silver technology derives from the shift of the country's economic center after the mideighth century CE.

Obviously, the shift of economic center resulted in the migration of official artisans from the capital in the north toward the economically thriving south [6]. Moreover, they also brought high metalworking skills to the southern regions. The rich mineral deposits in the south and more flexible mining policies provided abundant raw materials for the ample production of gold and silver vessels. The statistics showed that southern mining accounted for $92 \%$ of the country's gold production, and accounted for $94 \%$ of silver production [49]. Furthermore, the relatively unrestricted trading time and area promoted the further development of the economy in the south further [6]. Under this circumstance, the migrating artisans were able to show their talents to meet the market demands, and not just to cater to for the nobilities' tastes, which blossomed southern luxury industry and commerce, such as the gold and silver of Belitung Shipwreck [49]. The written record shows that five regions in the south, including Jiangnanxidao, frequently presented gold and silver artifacts to the imperial court [50]. This reflects that southern silver vessels after the mid-eighth century CE were probably even more loved by the imperial family, compared to the coetaneous northern silver vessels. Moreover, the currently studied silver box was produced in the late-ninth century $\mathrm{CE}$, thus it is expected that the silverwork techniques of southern China must have been well developed for almost 100 years.

Besides, noteworthy, Wensiyuan was established in the mid-ninth century and as the imperial workshop. Silver artifacts produced there catered to the imperial family's tastes and represented the aesthetics of society during that period. Among the silver artifacts uncovered from the pagoda crypt of Famen monastery, eight were the products of Wensiyuan [16]. All these northern-origin silver artifacts have a different decorative feature from the gilded silver box studied herein. Specifically, they have no decoration or process gilded 
motifs standing out on a smooth background [20]. Interestingly, most of the southern-origin silver artifacts recovered from the pagoda crypt of Famen monastery are endowed with complex decorations, including abundant motifs decoration and the use of ring-matted background. This type of decoration could be widely found on gold and silver vessels of southern-origin after the mid-eighth century $\mathrm{CE}$, such as the Dingmaoqiao treasure [6] and Belitung Shipwreck treasure [49]. More strikingly, this type of complex decoration also appears on the gold and silver artifacts of the early Tang period, such as the Hejiacun treasure [51]. Thus, it could be inferred that these delicate southern-origin silver vessels likely took over the decorative style of northern silver vessels before the mid-eighth century CE.

Consequently, these changes of decorations and differences in technical details indicate that southern artisans after the mid-eighth century CE inherited the decorative technology of the northern-origin silver vessels before the mid-eighth century CE and developed them to greater perfection.

\section{Conclusions}

The detailed technical analysis of southern-origin partially-gilded silver box from the Famen Monastery enhanced our understanding of the silverwork during the Tang dynasty after the mid-eighth century CE. The box consisted of five refined silver pieces, which were smelted by a commonly used silver refining technique during the Tang dynasty, i.e., cupellation. Furthermore, the results revealed that brazing, hammering, engraving, repoussé, chasing, punching, and partial fire-gilding were used to shape and decorate the box. Noteworthy, most of the aforementioned techniques were widely used during the Tang dynasty. Moreover, the $\mathrm{Ag}-\mathrm{Cu}$ alloy was utilized to bond the box bottom and ring foot. Strikingly, the similar decorative features among the south-made silver box after the mid-eighth century $\mathrm{CE}$ and north-made silver vessels before the mid-eighth century CE demonstrate the inheritance of decorative styles. Moreover, different technical skills of both types of silver vessels exhibit the evolution of decorative techniques, which resulted in attaining high perfection by the southern silversmiths after the downfall of northern China. The current study motivates further research on the comparative analysis of northern and southern silver vessels during the Tang dynasty.

\footnotetext{
Abbreviations

p-XRF: Portable X-ray fluorescence; Ag: Silver; Cu: Copper; Pb: Lead; Zn: Zinc; Hg: Mercury; Au: Gold; FM: Famen Monastery.
}

\section{Supplementary Information}

The online version contains supplementary material available at https://doi. org/10.1186/s40494-021-00531-2.

Additional file 1. Additional Figures S1-S7 and Table S1.

\section{Acknowledgements}

The authors thank the Institute of Historical Metallurgy and Materials in University of Science and Technology Beijing and Joint International Research Centre on Scientific Preservation of Cultural Heritage of "Belt and Road" for their supports. We also thank the Shaanxi Institute of Archaeology for providing the analytical equipment for conducting experiments. Special thanks go to Mr. Jie Jiang, Mr. Gaoju Zhang, and Mr. Hongzhe Luo from the Famen Temple Museum for their cooperation. We are also grateful to the three anonymous reviewers and editors for their valuable comments and suggestions.

\section{Authors' contributions}

PT designed and performed the experiments, analyzed the experimental data, and wrote the manuscript. JY directed the study. XR provided the partially gilded silver box for analysis. All authors read and approved the final manuscript.

\section{Funding}

Humanities and Social Science Foundation of Ministry of Education of China (2OYJAZH071).

\section{Availability of data and materials}

All data generated or analyzed during this study are included in this article and its additional file.

\section{Declaration}

\section{Competing interests}

The authors declare that they have no competing interests.

\section{Author details}

${ }^{1}$ State Key Laboratory of Solidification Processing, Center for Nano Energy Materials, School of Materials Science and Engineering, Northwestern Polytechnical University, 127 Youyi Road, Xi'an 710072, China. ${ }^{2}$ Institute of Culture and Heritage, Northwestern Polytechnical University, 127 Youyi Road, Xi'an 710072, China. ${ }^{3}$ Famen Temple Museum, Famen County, Baota Road, Baoji 722201, China.

Received: 28 January 2021 Accepted: 10 May 2021

Published online: 20 May 2021

\section{References}

1. Shang G. History of arts and crafts of the Tang dynasty. Hangzhou: Zhejiang Literature \& Art Publishing House; 1998. (in Chinese).

2. Kieser A. A "golden age" just for the living? silver vessels in Tang dynasty tombs. Tang Studies. 2015;33(1):62-90.

3. Kelley CW. Tang gold and silver. In: Kelley CW, editor. Chinese gold and silver in American collection: Tang Dynasty A. D., 618-907. Dayton: The Dayton Art Institute; 1984. p. 18-25.

4. Gyllensvärd B. T'ang gold and silver. Bull Museum Far Eastern Antiquities (Stockholm). 1957;29:1-230.

5. Rawson J. The ornament on Chinese silver of the Tang dynasty (Ad 618-906). In: British Museum Occasional Paper No. 40. Department of Oriental Antiquities; 1982.

6. Qi D. Research on Tang gold and silver vessels. Beijing: China Social Sciences Press; 1999. (in Chinese)

7. Rawson J. Ornament in China. In: Powers MJ, Tsiang KR, editors. A companion to Chinese art. West Sussex: John Wiley \& Sons; 2015. p. 371-91.

8. Marshak BI. A Sogdian silver bowl in the Freer Gallery of Art. Ars Orientalis. 1999;29:101-10. 
9. Graff DA. The reach of the military: tang. J Chinese History. 2017;1 (2):243-68.

10. Skaff JK. Barbarians at the Gates? The Tang Frontier Military and the An Lushan Rebellion. Int J Phytorem. 2013;21(1):23-35.

11. Ran W. Discoveries and features of southern silver vessels of Tang dynasty. J Northwest Univ. 1994;24(4):94-8 (in Chinese).

12. Ran W. Discoveries and features of northern silver vessels of Tang dynasty. Relics Museol. 1997;5:56-60 (in Chinese).

13. Ma Q, Scott AD. Metallographic study of gilded silver cup from Dachangling tomb of Tang dynasty in Sunanyugu autonomous county, Gansu province. In: Chinese Materials Research Society, editor. Proceedings of materials conference of China in 2002. Beijing: Metallurgical Industry Press; 2003. p. 2104-7 (in Chinese)

14. Tan P, Yang J, Li X. Primary study on silver vessels from Wei family cemetery of the Tang dynasty in Xi'an Shaanxi province. Res Qian Mausoleum Cult. 2014:8:38-49 (in Chinese)

15. Yao Z, Gong Y. Study on a silver box unearthed from the Tang dynasty (AD 618-907) tomb at Xiaolizhuang site, Henan province, China. Herit Sci. 2019;7(1):72.

16. Shaanxi Institute of Archaeology, Famen Museum, Baoji Cultural Heritage Administration, Fufeng Museum. Excavation report of Famen Temple: I. Beijing: Cultural Relics Press; 2007 (in Chinese).

17. Eugene YW. Of the true body: The Famen Monastery relics and corporeal transformation in Tang imperial culture. In: Wu H, Katherine RT, editors. Body and face in Chinese visual culture. Boston: Harvard University Asia Center; 2005

18. Ge C. Treasures from Famen Monastery and Neiku of Tang dynasty. In: Zhang Q, Han J, editors. Proceedings of the 1st international symposium on history and culture of Famen Monastery. Xi'an: Shaanxi People's Education Press; 1992. p. 75-80 (in Chinese).

19. Lu Z. Some thoughts about gold and silver from crypt of Famen Monastery. Archaeology. 1990;7:638-44 (in Chinese).

20. Shaanxi Institute of Archaeology, Famen Museum, Baoji Cultural Heritage Administration, Fufeng Museum. Excavation report of Famen Temple: II. Beijing: Cultural Relics Press; 2007 (in Chinese).

21. Wang Q. Diwang Bu. In: Cefu Yuangui: I (Photocopy). Beijing: Zhonghua Book Company; 1960. p. 1-181 (in Chinese)

22. Schutt AZ. Repousse is an ancient art. Design. 1941;42(5):21.

23. Untracht O. Jewelry: concepts and technology. New York: Doubleday, Knopf Doubleday Publishing Group, Inc; 2011.

24. Maryon H. Metal working in the ancient world. Am J Archaeol. 1949;53(2):93-125.

25. Goldberger G. Treatise on chasing and repoussé. Master Dissertation, School of Art (CIAS), Rochester Institute of Technology; 1972.

26. Fregni EG. The compleat metalsmith: Craft and technology in the British Bronze Age. Doctoral Dissertation, University of Sheffield; 2014

27. Destrée M. Repoussé, stamping, chasing, punching. In: Hackens T, Winkes $R$, editors. Gold jewelry: craft, style and meaning from Mycenae to Constantinopolis. Louvain-la-Neuve: Institut Superieur d'Archaeologie et d'Histoire De l'art, College Erasme; 1983. p. 171-80.

28. Anheuser K. The practice and characterization of historic fire gilding techniques. J Miner Metals Mater Soc. 1997;49(11):58-62.

29. Oddy A. Gilding of metals in the Old world. In: Niece SL, Craddock P, editors. Metal plating and patination: cultural, technical and historical developments. Oxford: Butterworth-Heinemann Ltd; 1993. p. 171-81.

30. Oddy WA. Gilding: an outline of the technological history of the plating of gold on to silver or copper in the Old World. Endeavour. 1991;15(1):29-33.

31. Yi B. The primary study of silver smelting in Tang dynasty. Cultural Relics. 1972;6:40-5 (in Chinese)
32. Craddock PT. Early metal mining and production. Edingburgh: Edinburgh University Press; 1995.

33. Forbes RJ. Studies in ancient technology. Leiden: E.J. Brill; 1971.

34. Gale NH, Stos-Gale ZA. Cycladic lead and silver metallurgy. Annu Br Schl Athens. 1981;76:169-224.

35. Liu S, Rehren T, Qin D, Chen J, Zhou W, Martinón-Torresf M, et al. Coalfuelled crucible lead-silver smelting in 12th-13th century China: a technological innovation in the age of deforestation. JAS. 2019;104:75-84.

36. Kassianidou V. Early extraction of silver from complex polymetallic ores. In: Craddock PT, Lang J, editors. Mining and metal production through the ages. London: British Museum Press; 2003. p. 198-206.

37. Bayley J. Medieval precious metal refining-archaeology and contemporary texts compared. In: Martinón-Torres M, Rehren T, editors. Archaeology, history and science: Integrating approaches to ancient materials. Walnut Creek: Left Coast Press; 2008. p. 131-50

38. Caro TD, Riccucci C, Parisi El, Faraldi F, Caschera D. Ancient silver extraction in the Montevecchio mine basin (Sardinia, Italy): micro-chemical study of pyrometallurgical materials. Appl Phys A Mater Sci Process. 2013;113(4):945-57.

39. Gomesa SS, Araújoa MF, Soaresa AMM, Pimentab J, Mendesb H. Lead provenance of Late Roman Republican artefacts from Monte dos Castelinhos archaeological site (Portugal): Insights from elemental and isotopic characterization by Q-ICPMS. Microchem J. 2018;141:337-45.

40. Anguilano L, Rehren T, Müller W, Rothenberg B. The importance of lead in the silver production at Riotinto (Spain). ArcheoSciences. 2010;34:269-76.

41. Ban G. Traditions of the Western Regions: Part 1. In: Book of Han. Beijing: Zhonghua Book Company; 1962. p. 3871-900 (in Chinese).

42. Su J. Yushi Dengbu Xiapin. In: Xinxiu Bencao. Hefei: Anhui Science and Technology Press; 1981. p. 127-46 (in Chinese).

43. Yang X. Fine gold artifacts and their techniques of China. Beijing: China Science Publishing \& Media Ltd. (CSPM); 2008 (in Chinese)

44. Wang S. Wanshoushan Guangchusi Ciqiku Tongzuo, Xizuo Zeli, Neigongyouzuo Xianxingzeli. In: Qingdaijiangzuozelihuibian, vol. 1. Henan: Elephant Press; 2000. p. 1181-218 (in Chinese).

45. Zheng F. Zuo Zhaojingjing. In: Han Y, Xu C, editors. Jinginglingchiyizhu, vol. 4. Shanghai: Shanghai Guji Press; 2015. p. 276-96 (in Chinese).

46. Mongiatti A, Suleman F, Meeks N. Beauty and belief: The endangered tradition of Omani silver jewellery. Br Museum Tech Res Bull. 2011;5:1-13.

47. Okamoto H, Schlesinger ME, Mueller EM. ASM handbook, Vol. III: alloy phase diagrams. USA: ASM International; 1992.

48. Kharakwal JS, Gurjar LK. Zinc and brass in archaeological perspective. Ancient Asia. 2006:1:139-59.

49. Krahl R, Guy J, Wilson JK, Raby J, editors. Shipwrecked: Tang treasures and monsoon winds. Singapore: Arthur M. Sackler Gallery, Smithsonian Institution, National Heritage Board of Singapore, Singapore Tourism Board; 2010.

50. Ouyang X, Song Q. Geography. In: New book of Tang. Beijing: Zhonghua Book Company; 1975 (in Chinese).

51. Shaanxi History Museum, School of Archaeology and Museology at Peking University, Aurora Center for Study of Ancient Civilizations of Peking University. Selected treasures from Hejiacun Tang hoard. Beijing: Cultural Relics Press; 2003. (in Chinese).

\section{Publisher's Note}

Springer Nature remains neutral with regard to jurisdictional claims in published maps and institutional affiliations. 